\title{
Efeitos Comportamentais e Imunológicos da Fluoxetina em Ratos Submetidos ao Nado Forçado
}

\author{
Eduardo Vignoto Fernandes \\ Solange de Paula Ramos \\ Celio Estanislau \\ Emerson José Venancio ${ }^{1}$ \\ Universidade Estadual de Londrina
}

\begin{abstract}
RESUMO - No presente trabalho, os efeitos comportamentais e imunomoduladores da fluoxetina foram avaliados num modelo animal de depressão, o nado forçado. Nesse, o comportamento de flutuar é sensível a antidepressivos e é usado como índice de desespero comportamental. Foram utilizados dois grupos experimentais, sendo um grupo controle tratado com salina e outro grupo teste tratado com a fluoxetina, ambos administrados por via intra-peritoneal. Os animais foram tratados três vezes ao dia por 12 dias. Adicionalmente, a resposta imune humoral a uma imunoestimulação (hemácias de carneiro) foi avaliada. A fluoxetina provocou aumento no tempo em flutuação, queda na massa corporal e menor produção total de anticorpos. Os resultados indicam uma modulação simultânea do comportamento e do sistema imunológico pela fluoxetina.
\end{abstract}

Palavras-chave: imunomodulação, massa corporal, nado forçado, fluoxetina.

\section{Behavioral and Immunological Effects of Fluoxetine in Rats Submitted to Forced Swimming}

\begin{abstract}
In the present study, behavioral and immunomodulatory effects of fluoxetine were evaluated with the forced swim test, an animal model of depression. In this model, floating behavior is responsive to antidepressants and is used as a behavioral index of despair. During 12 days, three times a day, two groups were treated intraperitoneally with saline or fluoxetine. Additionally, the humoral immune response to immunostimulation (sheep red blood cells) was evaluated. The animals treated with fluoxetine floated longer, showed decreases in body mass and had lower total production of antibodies. The results indicate simultaneous modulation of behavior and antibody production by fluoxetine.
\end{abstract}

Keywords: immunomodulation, body weight, forced swimming, fluoxetine.

A depressão é caracterizada por humor deprimido, desamparo e perda de interesse ou da capacidade de obter prazer em virtualmente todas as atividades. Ao experimentar um episódio de depressão, muitas pessoas também apresentam alterações no sono e no apetite, dificuldades de concentração, sentimentos de culpa e ideações, ou até mesmo tentativas de suicídio (American Psychiatric Association, 2000). Dados de prevalência indicam que, ao longo da vida, de 10 a $25 \%$ das mulheres e de 5 a $12 \%$ dos homens podem ser acometidos pelo transtorno (American Psychiatric Association, 2000), o que, junto ao grau incapacitante e ao sofrimento implicado, torna pertinente a investigação da depressão e de seus possíveis tratamentos.

Além das alterações psicológicas mencionadas acima, a depressão pode interferir no funcionamento do sistema imunológico (Altenburg et al., 2002). O sistema imunológico é formado por um conjunto de mecanismos de proteção do organismo contra elementos estranhos (Guyton \& Hall, 2002). A ação coordenada de células e diversos tipos de moléculas

1 Endereço para correspondência: Universidade Estadual de Londrina, Campus Universitário, Centro de Ciências Biológicas, Departamento de Ciências Patológicas, Rodovia Celso Garcia Cid, Pr 445 Km 380. Londrina,PR. CEP 86051-980. Fone: (43) 3371-5732. E-mail:emersonj@uel.br. à presença de tais elementos é chamada de resposta imunológica (Abbas, Lichtman, \& Pillai, 2012). Robles, Glaser e Kiecolt-Glaser (2005) apontam que a depressão exacerba a produção de citocinas (moléculas que promovem a interação célula-célula no sistema imunológico) pró-inflamatórias e a defesa do hospedeiro contra microrganismos patogênicos, entretanto essa hiperativação do sistema imunológico pode acarretar lesões teciduais. Diversos estudos encontraram evidências de que o indivíduo depressivo apresenta níveis elevados de citocinas pró-inflamatórias como a interleucina 2 (IL-2), interleucina 6 (IL-6) e interferon-alfa (IFN- $\alpha$ ) (Seidel et al., 1995; Vismari, Alves, \& Palermo-Neto, 2008) e supressão das células T auxiliares (células fundamentais para a resposta imunológica), comprometendo de forma direta e/ou indireta a imunidade do hospedeiro frente aos patógenos (Miller, 2010).

$\mathrm{O}$ uso de antidepressivos no tratamento de pacientes com depressão iniciou-se no fim dos anos 50 , sendo que desde então novos tratamentos foram desenvolvidos e tem constituído oportunidade para a compreensão dos mecanismos envolvidos na depressão (Deitos et al., 1999). Somente duas classes de antidepressivos eram conhecidas até a década de 80 , os tricíclicos e os inibidores de monoaminoxidase. Apesar de eficazes, essas drogas são inespecíficas e acarretam diversos efeitos colaterais (Moreno, Moreno, \& Soares, 
1999). Nas últimas décadas, outras classes de antidepressivos foram desenvolvidas. Os inibidores seletivos da recaptação de serotonina pertencem a essa nova geração de drogas antidepressivas, sendo a fluoxetina a droga mais prescrita para o tratamento da depressão, devido a sua eficácia, segurança e tolerabilidade (Leite et al., 2007; Egeland, Warner-Schmidt, Greengard, \& Svenningsson, 2010). A droga é ainda frequentemente usada para tratamento de outras condições (as quais não são objeto do presente estudo), tais como diferentes transtornos de ansiedade e transtornos alimentares, embora, nesse último caso, seu uso seja muito controverso (Duvvuri, Bailer, \& Kaye, 2010).

A investigação experimental da depressão em humanos é, em grande parte, eticamente inviável. Assim, modelos animais de depressão foram desenvolvidos para esse fim (Willner, 1991). O teste de nado forçado é um modelo muito utilizado para a avaliação de atividade antidepressiva com roedores (Porsolt, Le Pichon, \& Jalfre, 1977). Esse teste é baseado na observação de que ratos, quando colocados num cilindro com água de forma a não haver possibilidade de fuga dessa situação, apresentam comportamentos passivos (flutuação). Esses comportamentos, num reteste 24 horas após a primeira exposição, podem ser reduzidos por meio de tratamento com drogas antidepressivas, o que sugere algum elemento em comum com a depressão humana. Sua grande utilização decorre principalmente pela fácil execução, fidedignidade dos resultados em vários laboratórios e sua sensibilidade à ação de quase todas as classes de antidepressivos existentes na atualidade (Borsini \& Meli, 1988; Cryan \& Lucki, 2000).

Existe a sugestão de que o estresse está envolvido na depressão (Guimarães, 1999) e modelos animais como o teste do nado forçado e o desamparo aprendido são muitas vezes vistos como estressantes. Modelos animais de estresse e/ou de depressão têm mostrado alterações no sistema imunológico, incluindo o aumento na produção de IL-1 e do número de neutrófilos circulantes e menor resistência a infecção por bactérias (Kubera et al., 1996; Pedersen \& Hoffman-Goetz, 2000; Altenburg et al., 2002; Robles et al., 2005; Miller, 2010). Camundongos com predisposição a cataplexia (perda de tônus muscular), a qual pode ser revertida com antidepressivos, cinco dias após uma inoculação com hemácias de carneiro, caracterizaram-se por menor quantidade de linfócitos B que animais controle não-inoculados (Alperina, Kulikov, Popova, \& Idova, 2007).

A presente investigação foi elaborada com vistas a investigar os efeitos de um tratamento crônico com fluoxetina sobre o comportamento no teste do nado forçado em sessões repetidas e sobre a resposta imune humoral a um desafio com hemácias de carneiro.

\section{Método}

\section{Animais}

Foram utilizados 10 ratos adultos jovens (50-60 dias) Wistar machos (250-300 g), provenientes do Biotério
Central do Centro de Ciências Biológicas da Universidade Estadual de Londrina. O trabalho foi conduzido no biotério do Departamento de Psicologia Geral e Análise do Comportamento do Centro de Ciências Biológicas da Universidade Estadual de Londrina. Os ratos foram mantidos em gaiolas de polipropileno (40 $\mathrm{cm}$ x $34 \mathrm{~cm} \times 17 \mathrm{~cm}$ ) em número de cinco por gaiola. Aágua e a ração foram disponibilizadas $a d$ libitum durante todo o experimento (exceto durante a realização dos testes). A temperatura do biotério foi mantida em aproximadamente $25^{\circ} \mathrm{C}$, tendo sido estabelecido um ciclo de 12:12 horas de claro/escuro (luzes acesas a partir das 7:00 da manhã). A massa corporal dos animais foi mensurada diariamente para a definição da dose que cada animal iria receber de droga ou salina. Os procedimentos experimentais foram realizados em conformidade com o Comitê de Ética em Experimentação Animal da Universidade Estadual de Londrina, projeto $n^{\circ} 6977$, processo $n^{\circ} 16828 / 2010$.

\section{Nado Forçado}

O modelo de nado forçado foi realizado de acordo com Lucki (1997). Os animais foram submetidos ao teste em cilindros de PVC preto ( $50 \mathrm{~cm}$ de altura e $22 \mathrm{~cm}$ de diâmetro) com água na profundidade de $30 \mathrm{~cm}$ e temperatura média de $25 \pm 2^{\circ} \mathrm{C}$, os testes foram realizados individualmente por 15 minutos em 12 dias consecutivos, das 12:00 às 14:00 horas. Ao terminar o teste cada animal era retirado do cilindro e seco com toalha. Entre as sessões, a água do cilindro recém utilizado era escoada e o cilindro higienizado com álcool (75\%). Para o registro comportamental, os animais foram filmados com filmadora digital acoplada ao teto da sala de testes. Foram usados os primeiros cinco minutos do $2^{\circ}$ e $12^{\circ}$ dias. As filmagens foram arquivadas em computador. $\mathrm{O}$ tempo gasto nos seguintes comportamentos foi mensurado: flutuação (completa imobilidade ou movimentos suaves, apenas o suficiente para manter o nariz/cabeça acima da superfície da água); escalada (movimentos vigorosos com as patas dianteiras acima da superfície da água ou contra a parede do cilindro); natação (o animal se movimenta dentro do cilindro com o corpo na horizontal, sem quebrar a superfície da água com as patas dianteiras. Também foi considerado natação quando o animal manteve o corpo abaixo da superfície da água). $\mathrm{O}$ registro comportamental foi realizado por um observador treinado (o observador registrou duas vezes uma amostra de sessões e obteve concordância intra-observador superior a $85 \%$ ).

\section{Administração de Fluoxetina}

Após a primeira sessão no teste de nado forçado (pré-teste), os ratos passaram a receber intraperitonialmente (i.p.) três doses diárias de fluoxetina $10 \mathrm{mg} / \mathrm{kg}$ (Sigma) diluída em salina ou apenas salina 23:30 h, $5 \mathrm{~h}$ e $1 \mathrm{~h}$ antes do próximo teste de nado forçado, em um procedimento similar ao de outro trabalho (Porsolt et al., 1977). Esse procedimento foi repetido por doze dias consecutivos $\left(1^{\circ}\right.$ ao $\left.12^{\circ}\right)$. 


\section{Imunização e Coletas de Sangue}

Após a $5^{\mathrm{a}}$ sessão de nado forçado, todos os animais foram sedados por inalação não letal de éter etílico. A seguir foi realizada uma coleta de $500 \mu 1$ de sangue por punção cardíaca e uma inoculação i.p. com $250 \mu 1$ de solução de hemácia de carneiro a 2,5\%. O sangue coletado foi armazenado em tubos plásticos de 1,5 ml, contendo EDTA 5\%. Após a $12^{\mathrm{a}}$ sessão de nado, o procedimento de sedação foi repetido e houve uma coleta de $1,5 \mathrm{ml}$ de sangue. Após esse procedimento, os animais foram mortos por inalação de dose letal de éter etílico.

\section{Hemaglutinação}

Inicialmente, sangue de carneiro foi coletado em tubos de vidro com solução de Alsever (Glicose 20,5g; Citrato de sódio $8 \mathrm{~g}$; Cloreto de sódio 4,2 g, água destilada q.s.p. $1000 \mathrm{ml} \mathrm{e}$ ácido cítrico para ajuste do $\mathrm{pH}$ em 6,1) v/v. Posteriormente esse sangue foi centrifugado a $2000 \mathrm{rpm}$ por $5 \mathrm{~min}$ em temperatura ambiente (TA). Após a centrifugação foi descartada a camada leucocitária e o sobrenadante. As hemácias foram suspendidas em PBS 1X pH 7,2 e centrifugadas novamente a $2000 \mathrm{rpm}$ por $5 \mathrm{~min}$. Esse procedimento foi repetido por mais duas vezes.

Para a determinação dos títulos de anticorpos totais, as amostras de plasma foram inativadas a $56^{\circ} \mathrm{C}$ por 30 minutos e diluídas serialmente (fator 2) em placas de microtitulação com fundo em U. Para isso, foram aplicados $25 \mu 1$ de PBS $1 \mathrm{X}$ em doze poços (orifícios na placa). Então, no $1^{\circ}$ poço foi aplicado $25 \mu \mathrm{l}$ de plasma inativado. Após a homogeneização, $25 \mu \mathrm{l}$ foram transferidos para o $2^{\circ}$ poço e assim sucessivamente até o $11^{\circ}$ poço. $\mathrm{O} 12^{\circ}$ poço serviu como o controle negativo e não recebeu amostra de plasma.

Para a determinação dos títulos de anticorpos da classe $\mathrm{IgG}$, as amostras de plasma, previamente inativadas, foram incubadas com igual volume de 0,2 M 2-mercaptoetanol preparado em PBS $1 \mathrm{X}$ pH 7,2 por 30 minutos a $37^{\circ} \mathrm{C}$, a seguir os processos de diluição e divisão do plasma foram os mesmos descritos acima.

Após a diluição das amostras foi adicionado $25 \mu 1$ de hemácia de carneiro a $2 \%$ e a microplaca foi incubada por 2 horas a TA e 22 horas a $4^{\circ} \mathrm{C}$. O título foi considerado como a maior diluição em que se observa uma aglutinação positiva das hemácias.

\section{Análises Estatísticas}

Após constatação da normalidade pelo teste de Shapiro-Wilk, os resultados obtidos foram agrupados em valores de média e erro-padrão da média utilizando-se do programa Statistica $5.0^{\circledR}$. Foi utilizado o Teste $t$ de Student para comparar os grupos quanto à variação na massa corporal. Foram também realizadas análises de variância (ANOVA) de duas vias para medidas repetidas com o fator droga entre sujeitos (Fluoxetina X Salina) e o fator intra sujeitos imunização (pré X pós) para a produção de anticorpos ou sessão $\left(2^{\mathrm{a}} \mathrm{X} 12^{\mathrm{a}}\right)$ para as medidas comportamentais. Sempre que necessário, comparações post hoc foram realizadas com o teste de Tukey HSD. O índice de significância adotado foi de $p<0,05$.

\section{Resultados}

A Figura 1 mostra os valores da produção de anticorpos totais dos animais salina e fluoxetina. AANOVA mostrou que não houve efeito da fluoxetina $[\mathrm{F}(1,8)=0,595 ; p>0,05)$, e houve efeito da repetição de sessões $[\mathrm{F}(1,8)=25,928 ; p<$ $0,001)$, não existindo interação entre esses fatores $[\mathrm{F}(1,8)$ $=0,595 ; p>0,05)$. Na comparação entre os momentos pré e pós-imunização, o teste de Tukey HSD mostrou aumento na produção de anticorpos totais apenas no grupo controle. Os anticorpos totais detectados eram predominantemente da classe IgM, uma vez que as reações de hemaglutinação na presença de 2-mercaptoetanol foram todas negativas (Dados não mostrados).

\section{Produção de anticorpos}

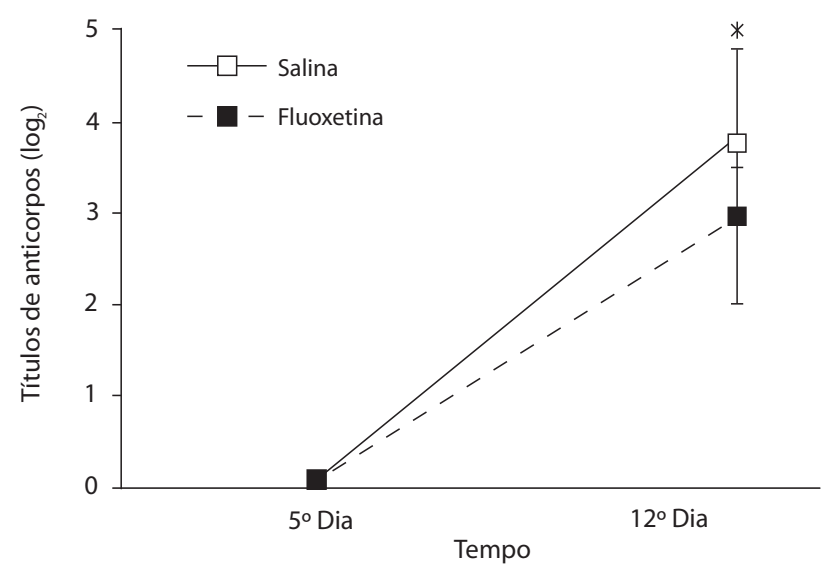

Figura 1. Variação na produção de anticorpos totais (média e erro padrão da média) por animais submetidos a sessões diárias de nado forçado (15 min) por 12 dias. São comparados o momento imediato pré-imunização com hemácias de carneiro ( $\left.5^{\circ} \mathrm{Dia}\right)$ e sete dias depois. Nos 12 dias os animais foram tratados com fluoxetina $(10 \mathrm{mg} / \mathrm{kg})$ três vezes por dia ou salina. *, diferença entre o $5^{\circ}$ e o $12^{\circ}$ dias, $\mathrm{p}<0,05$ (Tukey HSD).

Houve uma mudança significativa na massa corporal dos animais tratados com salina ou fluoxetina. O teste $t$ para amostras independentes mostrou diferença entre os grupos $[\mathrm{t}(8)=7,355 ; p<0,001]$ quanto à massa final, sendo que o grupo salina ganhou (inicial: $272,4 \pm 5,0 \mathrm{~g}$; final: $285,4 \pm 4,3$ $\mathrm{g}$ ), enquanto o grupo fluoxetina perdeu massa (inicial: 297,6 $\pm 10,3 \mathrm{~g}$; final: $279,0 \pm 10,1 \mathrm{~g}$ ).

Na Figura 2 são mostradas as durações do comportamento de escalar. A ANOVA mostrou que houve efeito da fluoxetina $[\mathrm{F}(1,8)=9,115 ; p<0,05)$ e da repetição de sessões $[\mathrm{F}(1,8)$ $=25,617 ; p<0,001]$, entretanto, não houve interação entre esses fatores $[\mathrm{F}(1,8)=0,502 ; p>0,05]$. Na comparação entre o segundo e o $12^{\circ}$ dia, o teste de Tukey HSD detectou queda apenas no tempo do grupo controle, mas não no do grupo fluoxetina. 


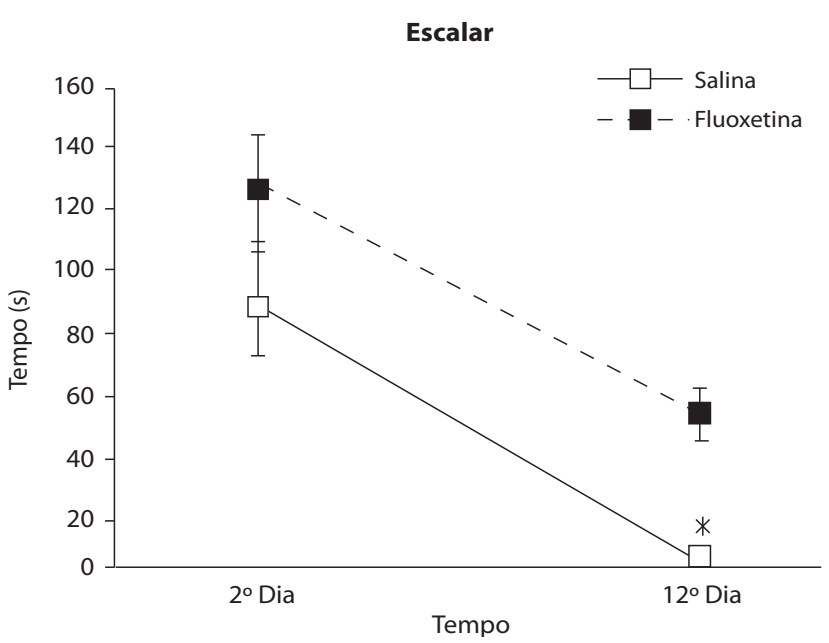

Figura 2. Tempo dispendido no comportamento de escalar (média e erro padrão da média) em sessões de nado forçado. Os animais foram tratados com fluoxetina $(10 \mathrm{mg} / \mathrm{kg})$ três vezes por dia ou salina. *, diferença entre o $2^{\circ}$ e o $12^{\circ}$ dias, $\mathrm{p}<0,05$ (Tukey HSD).

Sobre a duração do comportamento de nadar, a ANOVA mostrou que não houve efeito da fluoxetina $[\mathrm{F}(1,8)=0,612$; $p>0,05]$ nem da repetição de sessões $[\mathrm{F}(1,8)=2,708 ; p>$ $0,05]$. Entretanto, uma interação significativa entre esses fatores foi encontrada $[\mathrm{F}(1,8)=31,619 ; p<0,001]$ (Figura 3). Na comparação entre o segundo e o $12^{\circ}$ dia, o teste de Tukey HSD mostrou queda apenas no tempo do grupo controle, enquanto o grupo fluoxetina não apresentou alteração significativa. $\mathrm{O}$ teste ainda mostrou que, quando os grupos são comparados no $12^{\circ}$ dia, o grupo tratado com fluoxetina nadou por mais tempo.

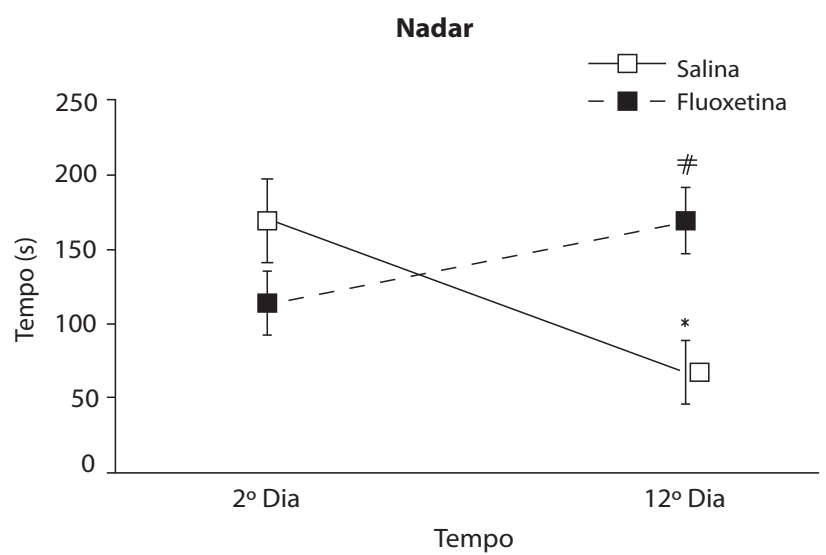

Figura 3. Tempo dispendido no comportamento de nadar (média e erro padrão da média) em sessões de nado forçado. Os animais foram tratados com fluoxetina $(10 \mathrm{mg} / \mathrm{kg})$ três vezes por dia ou salina. *, diferença entre o $2^{\circ}$ e o $12^{\circ}$ dias, $\mathrm{p}<0,01$ (Tukey HSD). \#, diferença entre os grupos no $12^{\circ}$ dia, $\mathrm{p}<0,01$ (Tukey HSD).

A Figura 4 mostra as durações do comportamento de flutuar. A ANOVA mostrou efeito da fluoxetina $[\mathrm{F}(1,8)=$ $6,420 ; p<0,05]$ e da repetição de sessões $[\mathrm{F}(1,8)=92,404$; $p<0,001]$ e interação entre esses fatores $[\mathrm{F}(1,8)=76,101$; $p<0,001]$. Na comparação entre o segundo e o $12^{\circ}$ dia,

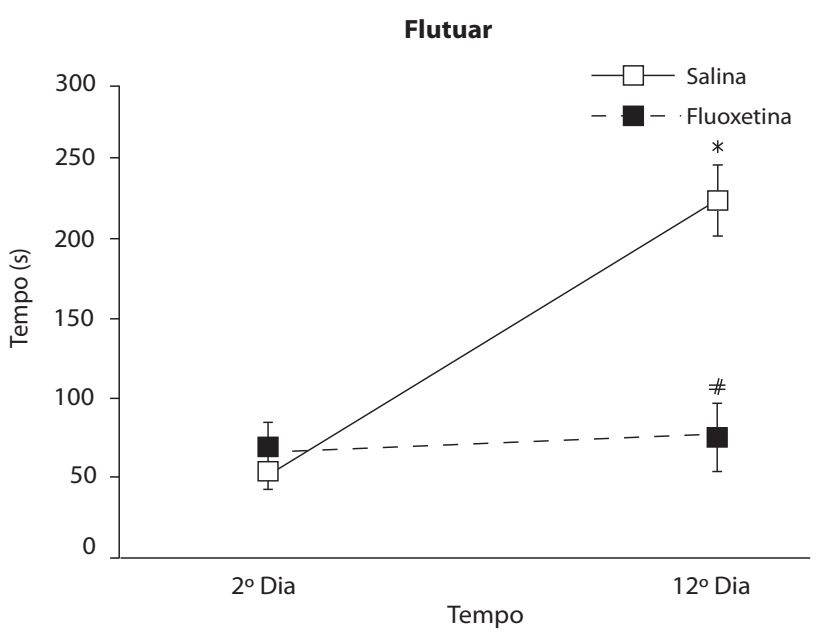

Figura 4. Tempo dispendido no comportamento de flutuar (média e erro padrão da média) em sessões de nado forçado. Os animais foram tratados com fluoxetina $(10 \mathrm{mg} / \mathrm{kg}$ ) três vezes por dia ou salina. *, diferença entre o $2^{\circ}$ e o $12^{\circ}$ dias, $p<0.001$ (Tukey HSD). \#, diferença entre os grupos no $12^{\circ}$ dia, $\mathrm{p}<0,001$ (Tukey HSD).

o teste de Tukey HSD detectou aumento apenas no grupo controle e não no grupo fluoxetina. $\mathrm{O}$ teste ainda mostrou que, quando os grupos são comparados no $12^{\circ} \mathrm{dia}$, o tratado com fluoxetina flutuou menos.

\section{Discussão}

O presente estudo investigou os efeitos da administração crônica de fluoxetina sobre a produção de anticorpos, a massa corporal e o comportamento de ratos submetidos diariamente por 12 dias ao teste do nado forçado, um modelo animal de depressão. Os resultados mostraram que os animais tratados com fluoxetina não tiveram o aumento na flutuação apresentado pelos tratados com salina. No mesmo sentido, as alterações na natação foram opostas entre os grupos, com os tratados com fluoxetina apresentando aumento nesse comportamento. Além disso, o tratamento com fluoxetina pareceu prevenir (ao menos parcialmente) uma queda no comportamento de escalar, como a observada no grupo tratado com salina. Ademais, o tratamento com fluoxetina levou à diminuição da produção de anticorpos, à perda de massa corporal.

$\mathrm{O}$ tratamento com fluoxetina atenuou o aumento na produção de anticorpos anti-hemácias de carneiro. Kennedy et al. (2005), ao submeterem ratos ao estresse agudo intenso de contenção, verificaram que o mesmo foi capaz de suprimir a produção de anticorpos produzidos contra antígenos $\mathrm{T}$ dependentes. Baldwin, Wilcox e Baylosis (1995), ao submeterem ratos a um regime de estresse que pode ser considerado subcrônico (nado forçado por 3-5 dias) após a imunização i.p. com hemácias de carneiro $(10 \%$ de $1 \mathrm{ml}$ de solução salina tamponada), não observaram diferença na produção de anticorpos entre ratos estressados e não estressados. Por outro lado, no presente estudo, a produção de anticorpos em resposta a uma imunização com uma quantidade 16 vezes menor de hemácias de carneiro foi sensível ao tratamento com fluoxetina. 
A ação imunossupressora da fluoxetina pode não ser restrita apenas à produção de anticorpos. Pellegrino e Bayer (2002) observaram que a proliferação in vitro dos linfócitos de ratos, os quais haviam recebido fluoxetina intraperitonealmente $(5 \mathrm{mg} / \mathrm{kg})$ duas horas antes de serem sacrificados, foi menor que a de seus respectivos controles. Esse resultado indica um papel imunossupressor desse antidepressivo para os linfócitos. Fazzino, Urbina, Cedeño e Lima (2009) verificaram que a administração de fluoxetina por três semanas desencadeou em ratos aumento dos linfócitos $T$ capazes de destruir células infectadas com antígenos (TCD8+) ao mesmo tempo que levou a diminuição de linfócitos $\mathrm{T}$ que desempenham papel de regulação da resposta imunológica (TCD4+). Com efeito, a fluoxetina pode ter um efeito imunoestimulador em algumas situações. Em camundongos foi observado que o estresse crônico de contenção acarreta diminuição dos linfócitos TCD4+ e manutenção dos linfócitos TCD8+ em comparação a controles não-estressados (Frick, Rapanelli, Cremaschi, \& Genaro, 2009). No entanto, o mesmo estudo mostrou que, quando tratados com fluoxetina, esses animais conseguiram restabelecer os valores iniciais de linfócitos TCD4+. Segundo Freire-Garabal et al. (1997) os camundongos estressados e tratados com fluoxetina apresentaram maior quantidade de linfócitos circulantes que os seus respectivos controles (estressados e não tratados com fluoxetina).

A ação imunomoduladora da fluoxetina provavelmente envolve a modulação da produção de citocinas. $\mathrm{O}$ tratamento de pacientes com diagnóstico de transtorno de depressão maior por 8 semanas com fluoxetina levou a uma normalização dos níveis de uma citocina pró-inflamatória (IL-6), os quais até então eram altos (Nishida et al., 2002). Frick et al. (2008), trabalhando com camundongos com câncer e os tratando com fluoxetina, observaram que esse antidepressivo leva ao aumento da produção de citocinas anti-tumorais (IFN- $\gamma$ e TNF- $\alpha$ ), resultando em menor taxa de crescimento tumoral e, consequentemente, em maior tempo de sobrevida. Por outro lado, Roumestan et al. (2007) verificaram efeito anti-inflamatório da fluoxetina $(5,10,15$ e $20 \mathrm{mg} / \mathrm{kg}$ ). Ao tratarem camundongos trinta minutos antes da inoculação com LPS, foi observada uma redução de até $60 \%$ nos níveis de TNF- $\alpha$ e de $50 \%$ na mortalidade, quando comparados ao grupo controle. Sacre, Medghalchi, Gregory, Brennan e Williams (2010) também observaram um efeito anti-inflamatório da fluoxetina em camundongos portadores de artrite reumatóide tratados com $25 \mathrm{mg} / \mathrm{kg}$ por sete dias: houve redução dos níveis de IL-12 e dos danos articulares. Porém, alguns estudos têm falhado em mostrar uma relação entre a fluoxetina e a modulação da produção de citocinas (Kubera et al., 2004; Maes et al., 1995; Jazayeri et al., 2010). Mesmo não sendo totalmente esclarecido o mecanismo de ação dos antidepressivos na regulação do sistema imunológico, sabe-se que o sistema nervoso está presente nos órgãos linfóides (responsáveis pela produção, maturação e ativação das células imunológicas) e compartilha com as células do sistema imunológico a produção de neurotransmissores, neuro-hormônios, hormônios, citocinas e de seus receptores. Por isso, é esperado que as drogas que atuam no sistema nervoso possam modular (ativar ou suprimir) o sistema imunológico (Mravec et al., 2006).
Existem relatos de que a administração crônica dessa droga provoca perda de peso (Wellman, Jones, \& Miller, 2003) ou previne seu ganho (Gutiérrez et al., 2002). No presente estudo, a administração de fluoxetina por 12 dias levou a uma perda de peso (na comparação com o grupo tratado com salina). Por outro lado, em outro estudo a administração oral crônica de fluoxetina preveniu perdas de peso provocadas por estresse de contenção (Zafir \& Banu, 2007). É importante considerar que os procedimentos dos dois estudos diferem quanto ao grau de estresse gerado. Ou seja, enquanto o estresse provocado por $15 \mathrm{~min} / \mathrm{dia}$ de nado forçado não levou a perda de massa no presente estudo (houve ganho de $15 \mathrm{~g}$ ), naquele estudo a submissão a $4 \mathrm{~h}$ de contenção causou perda de massa. Portanto, a contenção pode ser mais estressante que o nado forçado. Juntos, os dois estudos indicam dois efeitos aparentemente opostos da fluoxetina: na presença de um estressor severo que provoca redução de massa, a droga previne tais perdas; enquanto na presença de um estressor moderado, a droga leva a perda de massa, o que sugere um efeito anoréxico. Em favor de efeito anoréxico da fluoxetina, existem também estudos que mostram reduções de massa corporal provocadas pela administração crônica de fluoxetina em humanos obesos (Wise, 1992; Guimarães, 2006).

Em nosso experimento, os resultados de nado forçado foram coerentes com os de outros estudos que validam esse teste como modelo de depressão (Cryan \& Lucki, 2000; Cryan, Page, \& Lucki, 2002). Os animais tratados com fluoxetina, mas não os com salina, mostraram uma queda significante, da $2^{\mathrm{a}}$ para a $12^{\mathrm{a}}$ sessão, no comportamento de escalar. No comportamento de nadar, por sua vez, a fluoxetina levou a uma inversão da tendência de queda, da $2^{\mathrm{a}}$ para a $12^{\mathrm{a}}$ sessão, observada no grupo controle. No comportamento de flutuar, por fim, a droga preveniu o aumento na duração observado nos animais que não a receberam. Condição relacionada aos achados de Cryan et al. (2002), na qual observaram que ratos tratados com fluoxetina se mostram mais ativos para o comportamento de nadar, reduzem o tempo no escalar e mantém inalterado o tempo de flutuação em relação ao pré-teste (primeiro contato dos animais com o teste) de nado forçado. Os antidepressivos atuam em regiões distintas do sistema nervoso central e são capazes de alterar comportamentos relacionados com anedonia e passividade. No teste do nado forçado, esse último efeito é observado na forma de redução no tempo de flutuação (comportamento passivo) e aumento no escalar e/ou nadar (comportamento ativo). Dessa forma, o comportamento ativo mais evidenciado (escalar e/ou nadar) é dependente da droga administrada (Cryan \& Lucki, 2000). Page, Detke, Kirby, e Lucki (1999) observaram redução na duração do comportamento de flutuar e aumento no de nadar em ratos tratados com fluoxetina. Carr, Schechter, e Lucki (2010), administrando em ratos $20 \mathrm{mg} / \mathrm{kg}$ de fluoxetina três vezes antes do teste de nado forçado, obtiveram resultados similares. Cryan e Lucki (2000), comparando a fluoxetina e a reboxetina, inibidores seletivos de receptação de serotonina e de noradrenalina, respectivamente, verificaram que ambas as drogas provocaram queda na duração da flutuação. Entretanto, a primeira droga aumentou a natação e a segunda, a escalada. 
Neste estudo foi observado que os animais tratados com fluoxetina e submetidos por doze dias a sessões de nado forçado apresentaram redução na massa corporal e menor produção de anticorpos totais quando comparados aos animais salina. Foi observado ainda que esses efeitos são simultâneos aos efeitos comportamentais da droga, indicando que ao haver tratamento da depressão com a mesma, deve-se levar em consideração tais efeitos.

\section{Referências}

Abbas, A. K., Lichtman, A. H., \& Pillai, S. (2012). Imunologia celular e molecular (7 $7^{\mathrm{a}}$ ed.). Rio de Janeiro, RJ: Elsevier.

Alperina, E. L., Kulikov, A. V., Popova, N. K., \& Idova, G. V. (2007). Immune response in mice of a new strain ASC (Antidepressants Sensitive Catalepsy). Bulletin of Experimental Biology and Medicine, 144, 221-223. doi: 10.1007/s10517-007-0294-5

Altenburg, A. S. P., Ventura, d. G., Da-Silva, V. A., Malheirosa, L. R., Castro-Faria-Neto, H. C., Bozza, P. T., \& Teixeira, N. A. (2002). The role of forced swim test on neutrophil leukocytosis observed during inflammation induced by LPS in rodents. Progress in Neuro-Psychopharmacology and Biological Psychiatry, 26, 891-895. doi: org/10.1016/S02785846(01)00335-9

American Psychiatric Association. (2000). Diagnostic and statistical manual of mental disorders ( $4^{\mathrm{a}}$ ed., text revision). Washington, DC: American Psychiatric Association.

Baldwin, D. R., Wilcox, Z. C., \& Baylosis, R. C. (1995). Impact of differential housing on humoral immunity following exposure to an acute stressor in rats. Physiology and Behavior, 57, 649653. doi: org/10.1016/0031-9384(94)00313-0

Borsini, F., \& Meli, A. (1988). Is the forced swimming test a suitable model for revealing antidepressant activity? Psychopharmacology, 94, 147-160. doi: 10.1007/ BF00176837

Carr, G. V., Schechter, L. E., \& Lucki, I. (2010). Antidepressant and anxiolytic effects of selective 5-HT6 receptor agonists in rats. Psychopharmacology, doi: 10.1007/s00213-010-1798-7

Cryan, J. F., \& Lucki, I. (2000). Antidepressant-like behavioral effects mediated by 5 -hydroxytryptamine $2 \mathrm{C}$ receptors 1 . E-The Journal of Pharmacology and Experimental Therapeutics, 295, 1120-1126. Retrieved from http://jpet.aspetjournals.org/ content/295/3/1120.long

Cryan, J. F., Page, M. E., \& Lucki, I. (2002). Noradrenergic lesions differentially alter the antidepressant-like effects of reboxetine in a modified forced swim test. E-European Journal of Pharmacology, 436, 197-205. Retrieved from http://neurobio. drexel.edu/pageweb/ejp.pdf

Deitos, F., Copette, F. R., Pasqualotto, A. C., Segat, F. M., Santos, R. P., \& Guillande, S. (1999). Antidepressivos e seus efeitos colaterais, quais são e como reconhecê-los. E-Revista Brasileira de Clinica Terapêutica, 25, 63-70. Retrieved from http://www.moreirajr.com.br/revistas.asp?fase=r003\&id materia $=1354$

Duvvuri, V., Bailer, U. F., \& Kaye, W. H. (2010). Altered Serotonin Function in Anorexia and Bulimia Nervosa. In C. P. Müller \& B. L. Jacobs (Eds.), Handbook of the behavioral neurobiology of serotonin (pp. 715-729). London, UK: Elsevier.
Egeland, M., Warner-Schmidt, J., Greengard, P., \& Svenningsson, P. (2010). Neurogenic effects of fluoxetine are attenuated in p11 (S100A10) knockout mice. Biological Psychiatry, 67, 1048-1056. doi: org/10.1016/j.biopsych.2010.01.024

Fazzino, F., Urbina, M., Cedeño, N., \& Lima, L. (2009). Fluoxetine treatment to rats modifies serotonin transporter and cAMP in lymphocytes, CD4+ and CD8+ subpopulations and interleukins 2 and 4. International Immunopharmacology, 9, 463-467. doi:org/10.1016/j.intimp.2009.01.011

Freire-Garabal, M., Nlifiez, M. J., Losada, C., Pereiro, D., Riveiro, M. P., Gonzalez-Patiao, E., . . . Rey-Mendez, M. (1997). Effects of fluoxetine on the immunosuppressive response to stress in mice. Life Sciences, 60, 403-413. doi: org/10.1016/ S0024-3205(97)00329-9

Frick, L. R., Rapanelli, M., Cremaschi, G. A., \& Genaro, A. M. (2009). Fluoxetine directly counteracts the adverse effects of chronic stress on $\mathrm{T}$ cell immunity by compensatory and specific mechanisms. Brain, Behavior, and Immunity, 23, 36-40. doi: org/10.1016/j.bbi.2008.06.010

Frick, L. R., Palumbo, M. L., Zappia, M. P., Brocco, M. A., Cremaschi, G. A., \& Genaro, A. M. (2008). Inhibitory effect of fluoxetine on lymphoma growth through the modulation of antitumor T-cell response by serotonin-dependent and independent mechanisms. Biochemical Pharmacology, 75, 1817-1826. doi: org/10.1016/j.bcp.2008.01.015

Guimarães, C. (2006). Tolerabilidade e eficácia da fluoxetina na redução de parâmetros antropométricos e metabólicos em mulheres obesas. Dissertação de Mestrado, Universidade de São Paulo, Ribeirão Preto.

Guimarães, F. S. (1999). Medicamentos antidepressivos e estabilizadores do humor. In F. G. Graeff \& F. S. Guimarães (Eds.), Fundamentos de psicofarmacologia (pp. 93-122). São Paulo, SP: Atheneu.

Gutiérrez, A., Saracíbar, G., Casis, L., Echevarría, E., Rodríguez, V. M., Macarulla, .. .Portillo, M. P. (2002). Effects of fluoxetine administration on neuropeptide $\mathrm{Y}$ and orexins in obese Zucker rat hypothalamus. Obesity Research, 10, 532-540. doi: 10.1038/ oby. 2002.72

Guyton, A. C., \& Hall, J. E. (2002). Tratado de fisiologia médica $\left(10^{\mathrm{a}}\right.$ ed.). Rio de Janeiro, RJ: Guanabara Koogan.

Jazayeri, S., Keshavarz, S. A., Tehrani-Doost, M., Djalali, M., Osseini, M., Amini, H., .. . Djazayery, A. (2010). Effects of eicosapentaenoic acid and fluoxetine on plasma cortisol, serum interleukin-1beta and interleukin-6 oncentrations in patients with major depressive disorder. Psychiatry Research, 178, 112-115. doi: org/10.1016/j. psychres.2009.04.013

Kennedy, S. L., Nickerson, M., Campisi, J., Johnson, J. D., Smith, T. P., Sharkey, C., \& Fleshner, M. (2005). Splenic norepinephrine depletion following acute stress suppresses in vivo antibody response. Journal of Neuroimmunology, 165, 150-160. doi: org/10.1016/j.jneuroim.2005.05.001

Kubera, M., Kenis, G., Bosmans, E., Kajta, M., Basta-Kaim, A., Scharpe, S., . . . Maes, M. (2004). Stimulatory effect of antidepressants on the production of IL-6. International Immunopharmacology, 4, 185-192. doi: org/10.1016/j.intimp. 2003.11.006 
Kubera, M., Symbirtsev, A., Basta-Kaim, A., Borycz, J., Roman, A., Papp, M., \& Claesson, M. (1996). Effect of chronic treatment with imipramine on interleukin 1 and interleukin 2 production by splenocytes obtained from rats subjected to a chronic mild stress model of depression. E-Polish Journal of Pharmacology, 48, 503-506. Retrieved from http://www.ncbi.nlm.nih.gov/ pubmed/9112692

Leite, C. E., Nunes, F. B., Pires, M. G. S., Lunardelli, A., Lhullier, F. R., Martins, M. R., \& Oliveira, J. R. (2007). Influência do uso continuado de fluoxetina nas dosagens séricas de prolactina em mulheres. E-Revista Brasileira de Análises Clínicas, 39, 283-285. Retrieved from http://www.sbac.org.br/pt/pdfs/rbac/ rbac_39_04/rbac_39_04_10.pdf

Lucki, I. (1997). The forced swimming test as a model for core and component behavioral effects of antidepressant drugs. Behavioral Pharmacology, 8, 523-532. doi: 10.1097/00008877199711000-00010

Maes, M., Meltzer, H. Y., Bosmans, E., Bergmans, R., Vandoolaeghe, E., Ranjan, R., \& Desnyder, R. (1995). Increased plasma concentrations of interleukin-6, soluble interleukin-6, soluble interleukin-2 and transferrin receptor in major depression. Journal of Affective Disorders, 34, 301-309. doi:org/10.1016/0165-0327(95)00028-L

Miller, A. H. (2010). Depression and immunity: A role for T cells? Brain, Behavior and Immunity. 24, 1-8. doi: org/10.1016/j. bbi.2009.09.009

Moreno, R. A., Moreno, D. H., \& Soares, M. B. M. (1999). Psicofarmacologia de antidepressivos. Revista Brasileira de Psiquiatria, 21, 24-40. doi: org/10.1590/S151644461999000500006

Mravec, B., Gidron, Y., Kukanova, B., Bizik, J., Kiss, A., \& Hulin, I. (2006). Neural-endocrine-immune complex in the central modulation of tumorigenesis: Facts, assumptions, and hypotheses. Journal of Neuroimmunology, 180, 104-116. doi:10.1016/j.jneuroim.2006.07.003

Nishida, A., Hisaoka, K., Zensho, H., Uchitomi, Y., Morinobu, S., \& Yamawaki, S. (2002). Antidepressant drugs and cytokines in mood disorders. International Immunopharmacology, 2, 1619-1626. doi: org/10.1016/S1567-5769(02)00190-X

Page, M. E., Detke, M. J., Kirby, A. D. L. G., \& Lucki, I. (1999). Serotonergic mediation of the effects of fluoxetine, but not desipramine, in the rat forced swimming test. Psychopharmacology, 147, 162-167. doi: 10.1007/ s002130051156

Pedersen, K. B., \& Hoffman-Goetz, L. (2000). Exercise and the immune system: regulation, integration and adaptation. E-Physiology Reviews, 80, 1055-1081. Retrieved from http:// physrev.physiology.org/content/80/3/1055.short

Pellegrino, T. C., \& Bayer, B. M. (2002). Role of central 5-HT2 receptors in fluoxetine-induced decreases in T lymphocyte activity. Brain, Behavior, and Immunity, 16, 87-103. doi: org/10.1006/brbi.2001.0625
Porsolt, R.D., Le Pichon, M., \& Jalfre, M. (1977). Depression: a new animal model sensitive to antidepressant treatments. Nature, 266, 730-732. doi:10.1038/266730a0

Robles, T. F., Glaser, R., \& Kiecolt-Glaser, J. K. (2005). A new look at chronic stress, depression, and immunity. Current Directions in Psychological Science, 14, 111-115. doi: 10.1111/j.09637214.2005.00345.x

Roumestan, C., Michel, A., Bichon, F., Portet, K., Detoc, M., Henriquet, C., . . . Mathieu, M. (2007). Anti-inflammatory properties of desipramine and fluoxetine. Respiratory Research, 8, 1-11. doi:10.1186/1465-9921-8-35

Sacre, S., Medghalchi, M., Gregory, B., Brennan, F., \& Williams, R. (2010). Fluoxetine and citalopram exhibit potent antiinflammatory activity in human and murine models of rheumatoid arthritis and inhibit toll-like receptors. Arthritisand rheumatism, 62, 683-693. doi: 10.1002/art.27304

Seidel, A., Arolt, V., Hunstiger, M., Rink, L., Behnisch, A., \& Kirchner, H. (1995). Cytokine production and serum proteins in depression. Scandinavian Journal of Immunology, 41, 534-538. doi: 10.1111/j.1365-3083.1995.tb03604.x

Vismari, L., Alves, G. J., \& Palermo-Neto, J. (2008). Depressão, antidepressivos e sistema imune: um novo olhar sobre um velho problema. Revista de Psiquiatria Clínica, 35, 196-204. doi: org/10.1590/S0101-60832008000500004

Wellman, P. J., Jones, S. L., \& Miller, D. K. (2003). Effects of preexposure to dexfenfluramine, phentermine, dexfenfluraminephentermine, or fluoxetine on sibutramine-induced hypophagia in the adult rat. Pharmacology Biochemistry and Behavior, 75, 103-114. doi: org/10.1016/S0091-3057(03)00045-5

Willner, P. (1991). Behavioural models in psychopharmacology. In P. Willner (Ed.), Behavioural models in psychopharmacology: theoretical, industrial, and clinical perspectives (pp. 3-18). Cambridge: Cambridge University Press.

Wise, S. D. (1992). Clinical studies with fluoxetine in obesity. E-American Journal of Clinical Nutrition. 55, 181S-184S. Retrieved from http://www.ajcn.org/content/55/1/181S.short

Zafir, A., \& Banu, N. (2007). Antioxidant potential of fluoxetine in comparison to Curcuma longa in restraint-stressed rats. European Journal of Pharmacology, 572, 23-31. doi: org/10.1016/j.ejphar.2007.05.062

Recebido em 19.12.2010

Primeira decisão editorial em 29.05.2012

Versão final em 18.07.2012

Aceito em 23.07.2012 